\title{
Biochemical Markers, Body Composition and Risk of Cardiovascular Disease Amongst Geriatric Population in Al Madinah Al Munawarah: A Risk Assessment Study
}

Wala M Mohammedsaeed

Taibah University

AHLAM Badreldin EL SHIKIERI ( $\sim$ dn7shiki@hotmail.com )

Taibah University https://orcid.org/0000-0002-7508-5470

\section{Research note}

Keywords: Older adults, Cardiovascular disease risk, Biochemical markers, Body Composition, Al Madinah Al Munawarah, Saudi Arabia

Posted Date: August 7th, 2020

DOI: https://doi.org/10.21203/rs.3.rs-49554/v1

License: (c) (i) This work is licensed under a Creative Commons Attribution 4.0 International License.

Read Full License 


\section{Abstract}

Objective: to assess selected biochemical markers and body composition and their association with CVD risk amongst older adults in Al Madinah Al Munawarah, Saudi Arabia.

Results: Older adults had high glycated hemoglobin percent (women 7•90 $\pm 2 \cdot 95$; men $8 \bullet 4 \pm 1 \bullet 64, P$

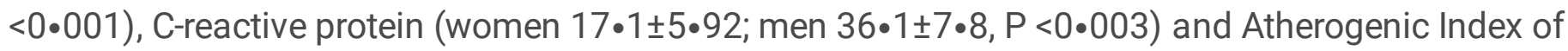
Plasma (AIP; women $0 \cdot 21 \pm 0 \cdot 18$; men $0 \cdot 22 \pm 0 \cdot 21, \mathrm{P}<0 \cdot 04$ ) with higher values amongst men compared to their counterparts. In addition, they suffered from hypoalbuminemia and low hemoglobin levels. Older adults were malnourished, either underweight (16\%) or overweight and obese (35\%). Based on their AIP, most of the participants had intermediate to high CVD risk. Multiple Linear Regression model with age as the dependent variable showed that the risk of CVD increased with higher BMI (women only: Odd ratio 6.99, 95\% Cl: 0.96-5.03, P <0.001), elevated triglycerides (women: Odd ratio 7.47, 95\% Cl: 0.16-3.17; men: Odd ratio: $6.55,95 \% \mathrm{Cl}$ : 0.23-3.26, $\mathrm{P}<0.001$ ), high C-reactive protein (Odd ratio 8.99, 95\% Cl: 0.99-6.00, $\mathrm{P}=$ 0.003; men: Odd ratio 4.00, 95\% Cl: 0.99-3.01, P < 0.002) and high AIP (women: Odd ratio $14.6,95 \% \mathrm{Cl}$ : 0.0.56-16.18, $\mathrm{P}=0.002$; men: Odd ratio $7.35,95 \% \mathrm{Cl}: 0.35-20.29, \mathrm{P}<0.001)$.

\section{Introduction}

The ageing process involves various physical and physiological changes including metabolic, neurological and immunological changes. ${ }^{[1]}$ Cardiovascular diseases (CVDs) are amongst the most-life threatening diseases worldwide and increase the risk of morbidity and mortality amongst aging adults. Although, the prevalence of patients with CVDs is 42,790 and 50,213 for women and men respectively, ${ }^{[2]}$ little is known about the risk among the Saudi older adults.

Traditionally, obesity, ${ }^{[3-6]}$ elevated blood pressure, ${ }^{[7-8]}$ lipid profile (including total cholesterol, low- and high-density lipoprotein cholesterol ${ }^{[9-10]}$ (LDL-C, HDL-C) and triglycerides concentrations), impaired fasting glucose and diabetes are the predictors of CVD risk, morbidity and mortality. ${ }^{[1-13]}$ Furthermore, serum proteins such as albumin and prealbumin are used to define the nutritional status of adults and predict CVD risk. ${ }^{[14]}$.

Non-traditional CVD risk factors include deficiencies of vitamins such as $B_{12}, B_{6}$, and folate, due to their association with hyperhomocysteinemia, a vascular risk factor that increases the risk of coronary heart disease. ${ }^{[15]}$ In addition, an increase in the inflammatory marker C-reactive proteins is an indication of cognitive and physical impairments and is being reported as a crucial predictor of CVD risk and reduced survival amongst older adults. ${ }^{[16]}$ Moreover, the Atherogenic Index of Plasma (AIP) which is the logarithm of triglycerides to HDL-C ratio, is shown to be a good predictor of the risk of all-cause deaths amongst the older adults and a useful non-traditional indicator for CVD risk. ${ }^{[17-18]}$ 
The determination of selected CVD risk factors helps in identifying those older adults who are at increased risk of morbidity and mortality, hence developing appropriate programs in the country. The current study aimed to determine the body composition, selected biochemical markers and CVD risk amongst free-living older Saudi men and women. It is hypothesized that older persons are at increased risk of CVD.

\section{Methods}

An epidemiological, cross sectional study was conducted between January 2018 to January 2020 targeting Saudi older aged $\geq 65$ years old living in Al Madinah Al Munawarah city with no history of myocardial infarction or stroke recruited from various community settings e.g. Mosques (for men) and religious schools (men and women). Relatives, friends and neighbors were also invited to participate. The sample size was determined based on the following equation:

$n=\left(Z_{1-a / 2}\right)^{2} x P(1-P) \div d^{2}$

Considering a confidence level of $95 \%, Z_{1-\alpha / 2}=1 \cdot 96, d=0.05$ and using a $3.5 \%$ malnutrition prevalence in this population. ${ }^{[19]}$

\section{Data Collection}

Socio-demographic data collected included age, gender, marital status, educational status, and smoking habits. Information was also obtained about the presence or history of diseases. Weight and height were measured twice using an electronic scale (Beurer GmbH Type PS 07, China) and BMI was calculated. Blood samples $(5 \mathrm{ml})$ were collected in plain and EDTA tubes and tests were done using the clinical chemistry automated machine Dimension X P and, Siemens Healthcare Diagnostics Ltd Frimley, Camberley, UK. The Atherogenic Index of Plasma (AIP) $=\log (T G / H D L-C)$ was calculated as an Atherogenic dyslipidemia index. Moreover, N-MID (Roche diagnostics, GmbH, Mannheim, German) and the Cobas e 411 immunoassay analyzer (Roch Diagnostics, GmbH, German) were used. The assay was based on chemiluminescence-immunoassay technology according to the manufacturer's instructions.

\section{Statistical analysis:}

Statistical analysis was performed by the software package known as Graphpad Prism 7 (GraphPad Software, CA, USA). Differences between older men and women were analyzed using Independent Student's $t$-test. Analysis of variance (ANOVA) analysis was used to find differences amongst selected biochemical markers and AIP categories. Pearson's correlation was used to determine the association between AIP and selected CVD risk factors. Multivariate analysis based on Multiple Linear Regression model was run to predict risk of CVD for older adults. Significance level was set at $<5 \%$. 


\section{Results}

Older adults $(n=600)$ aged $65-90$ years were included in the study with equal numbers of men and women. Their mean BMI was normal and most of them were married, had schooling education, living with their families and were non-smokers. In addition, more older men were employed $(P=0.04)$ and diabetic $(P=0.05)$ whereas more women were hypertensive (Table 1$)$. 
Table 1

Socio-demographic characteristics of older adults. Numbers, percentages and P-values are shown

\begin{tabular}{|c|c|c|c|}
\hline Variables & Women $(n=300)$ & Men $(n=300)$ & P-value \\
\hline & $\mathrm{n}(\%)$ & $\mathrm{n}(\%)$ & \\
\hline \multicolumn{4}{|l|}{ Age in years } \\
\hline Mean \pm SD & $74 \cdot 5 \pm 32 \cdot 8$ & $77 \pm 55 \cdot 8$ & $0 \cdot 08$ \\
\hline \multicolumn{4}{|l|}{$\operatorname{BMI}\left(\mathrm{Kg} / \mathrm{m}^{2}\right)$} \\
\hline Mean \pm SD & $23 \cdot 48 \pm 3 \cdot 69$ & $22 \cdot 18 \pm 9 \cdot 05$ & 0.11 \\
\hline Marital status: & & & \multirow[t]{5}{*}{$0 \cdot 72$} \\
\hline - Married & $226(75 \cdot 3)$ & $233(77 \cdot 6)$ & \\
\hline - Widow & $13(4 \cdot 3)$ & $17(5 \cdot 7)$ & \\
\hline - Divorced & $37(12 \cdot 3)$ & $30(10)$ & \\
\hline - Single & $24(8)$ & $21(7)$ & \\
\hline \multicolumn{3}{|l|}{ Educational level: } & \multirow[t]{4}{*}{$0 \cdot 84$} \\
\hline - Religious schools or illiterate & $45(15)$ & $30(10)$ & \\
\hline - Primary /secondary or senior school & $165(55)$ & $150(50)$ & \\
\hline - University education & $90(30)$ & $120(40)$ & \\
\hline \multicolumn{3}{|l|}{ Employment status: } & \multirow[t]{3}{*}{$0.04 *$} \\
\hline - Employed & $120(40)$ & $167(55 \cdot 7)$ & \\
\hline - Unemployed (retired) & $180(60)$ & $134(44 \cdot 7)$ & \\
\hline \multicolumn{3}{|l|}{ Living status: } & \multirow[t]{3}{*}{$0 \cdot 85$} \\
\hline - Living alone & $16(5 \cdot 3)$ & $32(10 \cdot 7)$ & \\
\hline - Living with family or relatives & $284(94 \cdot 7)$ & $268(89 \cdot 3)$ & \\
\hline \multicolumn{4}{|l|}{ Smoking habit: } \\
\hline - Smokers & $11(3 \cdot 7)$ & $92(30 \cdot 7)$ & $0.001 * *$ \\
\hline \multicolumn{4}{|l|}{ Presence of chronic disease: } \\
\hline - No chronic disease & $17(5 \cdot 7)$ & $9(3)$ & $0 \cdot 88$ \\
\hline - Diabetes Mellitus & $216(72)$ & $248(82 \cdot 7)$ & $0.05^{*}$ \\
\hline - Hypertension & $46(15 \cdot 3)$ & $33(11)$ & $0.04 *$ \\
\hline
\end{tabular}




\begin{tabular}{|llll|}
\hline Variables & Women $(n=\mathbf{3 0 0})$ & Men $(n=300)$ & P-value \\
\hline - Others§ & $21(7)$ & $10(3 \cdot 4)$ & 0.85 \\
\hline
\end{tabular}

\section{P-value obtained from Independent Student t-test• * $p<$ $0.05, * * p<0.001$.}

$\$$ Others included having more than one health problem and those with other diseases such as thyroid disorders, osteoporosis, gastrointestinal disorders, etc. •

When compared with normal laboratory values, the study indicated that both older men and women had higher fasting blood glucose, glycated hemoglobin A1C, total serum cholesterol, C-reactive proteins levels and AIP. On the other hand, they had lower hemoglobin, serum iron, serum albumin and vitamin $\mathrm{B}_{12}$ levels (Table 2). Although these biochemical markers are elevated for the older participants, women had better values than their counterparts in some of these markers. 
Table 2: Selected Biochemical markers for older Saudi men and women. Mean \pm SD, normal and Pvalues are shown

\begin{tabular}{|c|c|c|c|c|}
\hline Blood Test & $\begin{array}{l}\text { Women }(n= \\
300)\end{array}$ & $\begin{array}{l}\text { Men } \\
(n=300)\end{array}$ & P-value & Normal values \\
\hline $\begin{array}{l}\text { Fasting Blood Glucose } \\
(\mathrm{mmol} / \mathrm{L})\end{array}$ & $5 \cdot 77 \pm 5 \cdot 76$ & $6 \cdot 23 \pm 4 \cdot 32$ & 0.40 & $4 \cdot 6-6 \cdot 4$ \\
\hline Glycated Hemoglobin A1C (\%) & $7 \cdot 90 \pm 2.95$ & $8.4 \pm 1 \cdot 64$ & $\begin{array}{l}< \\
0.001^{* *}\end{array}$ & $4 \cdot 3-6 \cdot 0$ \\
\hline Hemoglobin level (g/dl) & $12 \cdot 6 \pm 3 \cdot 46$ & $12 \cdot 6 \pm 3 \cdot 46$ & $0 \cdot 27$ & $12-16$ \\
\hline Iron $(\mu \mathrm{mol} / \mathrm{L})$ & $7 \cdot 8 \pm 9 \cdot 83$ & $9 \cdot 8 \pm 3 \cdot 73$ & $0 \cdot 80$ & $9 \cdot 0-30 \cdot 4$ \\
\hline Ferritin ug/mL & $68 \cdot 12 \pm 14 \cdot 705$ & $\begin{array}{l}39 \cdot 12 \pm \\
12 \cdot 991\end{array}$ & $\begin{array}{l}< \\
0.001^{* *}\end{array}$ & 12 to 150 \\
\hline LDL-cholesterol (mmol/L) & $3 \cdot 23 \pm 0 \cdot 86$ & $2 \cdot 92 \pm 1 \cdot 02$ & $0 \cdot 87$ & $5 \cdot 2-6 \cdot 1$ \\
\hline HDL-cholesterol (mmol/L) & $1 \cdot 22 \pm 0 \cdot 31$ & $1 \cdot 02 \pm 0 \cdot 19$ & $\begin{array}{l}< \\
0.001^{* *}\end{array}$ & $1 \cdot 0$ \\
\hline Total cholesterol (mmol/L) & $6 \cdot 78 \pm 1 \cdot 14$ & $6 \cdot 63 \pm 1 \cdot 13$ & $0.04^{*}$ & $5 \cdot 3-6 \cdot 2$ \\
\hline Triglycerides (mmol/L) & $1 \cdot 27 \pm 0 \cdot 67$ & $1 \cdot 49 \pm 1 \cdot 1$ & $\begin{array}{l}< \\
0 \cdot 001^{* *}\end{array}$ & $0.40-1.52$ \\
\hline $\operatorname{ALT}(U / L)$ & $16 \pm 2 \cdot 01$ & $18 \pm 4 \bullet 01$ & $0 \cdot 01^{*}$ & $7-55$ \\
\hline AST (U/L) & $20 \cdot 0 \pm 9 \cdot 18$ & $19 \cdot 0 \pm 6 \cdot 18$ & 0.06 & $15 \cdot 1-46 \cdot 2$ \\
\hline Creatinine (mmol/L) & $57 \cdot 1 \pm 9 \cdot 83$ & $89 \cdot 1 \pm 10 \cdot 33$ & $\begin{array}{l}< \\
0 \cdot 001^{* *}\end{array}$ & $45-90$ \\
\hline C-reactive protein (mg/L) & $17 \cdot 14 \pm 5 \cdot 92$ & $36 \cdot 14 \pm 7 \cdot 82$ & $0 \cdot 003^{* *}$ & $0 \cdot 00-5 \cdot 00$ \\
\hline AIP & $0.21 \pm 0.18$ & $0.22 \pm 0.21$ & $0 \cdot 04^{*}$ & $0.11-0.21$ \\
\hline Albumin $(\mathrm{g} / \mathrm{L})$ & $33 \cdot 0 \pm 5 \cdot 21$ & $37 \cdot 0 \pm 7 \cdot 31$ & $0 \cdot 02^{*}$ & $35-55$ \\
\hline Vitamin $B_{12}(p m o l / L)$ & $220 \cdot 0 \pm 22 \cdot 80$ & $215 \pm 22 \cdot 78$ & $<0.05^{*}$ & $118-701$ \\
\hline
\end{tabular}

Results further revealed that more men (44\%) than women (26.4\%) were either overweight and/or obese. On the contrary, hypoalbuminemia was more common among women (54\%) than men (41\%). Based on their AIP results, the prevalence of intermediate to high CVD risk amongst men was significantly higher than women ( $55 \%$ versus $94 \%, \mathrm{P}=0 \cdot 003)$. Men $(57 \%)$ and women $(33 \%)$ also had high $\mathrm{C}$-reactive protein levels (Table 3). 
Table 3: Categories of Body composition and selected biochemical markers amongst Saudi old men and women. Number and percentages are shown ${ }^{\#}$

Women $\mathrm{n}(\%)$

BMI $\left(\mathrm{Kg} / \mathrm{m}^{2}\right)$

Underweight (< 18.5)

Normal weight ( $18 \cdot 5$ to 25$)$

Overweight (25 to $29 \cdot 9)$

Obese $(\geq 30)$

Albumin $(g / L)$

$<35$

$35-50$

$>50$

Hemoglobin $(\mathrm{g} / \mathrm{dl})$

$\mathrm{F}<12 \mathrm{~g} / \mathrm{dl} ; \mathrm{M}<14$

F 12 to $16 ; M 14$ to 18

$\mathrm{F}>16 ; \mathrm{M}<18$

Iron $(\mu \mathrm{mol} / \mathrm{L})$

$\mathrm{F}<11 ; \mathrm{M}<14$

F 11-29; M 14-32

$\mathrm{F}>29 ; \mathrm{M}>32$

Glycated hemoglobin A1C (\%)

Normal $<5 \bullet 7$

Pre-diabetic $5 \cdot 7 \%$ to $6 \cdot 4$

Diabetic $>6 \bullet 4$

Vitamin $\mathrm{B}_{12}(\mathrm{pmol} / \mathrm{l})$

$<118$

118-701

$74(24 \cdot 7)$

$149(49 \cdot 7)$

$68(22 \cdot 7)$

$11(2 \cdot 7)$

$163(54 \cdot 3)$

$126(42 \cdot 0)$

$9(3 \cdot 0)$

$122(40 \cdot 7)$

$176(58 \cdot 7)$

$2(0 \cdot 7)$

$201(67 \cdot 0)$

$90(30 \cdot 0)$

$9(3 \cdot 0)$

$60(20 \cdot 0)$

$24(8 \cdot 0)$

$216(72 \cdot 0)$
Men n (\%)

$23(7 \cdot 7)$

$125(41 \cdot 7)$

$110(36 \cdot 7)^{*}$

$22(7 \cdot 3)$

$122(40 \cdot 7)$

$177(59 \cdot 0)$

$1(0 \cdot 3)^{*}$

162 (54)

$135(45)$

$3(1)$

$253(84 \cdot 3)$

$49(16 \cdot 3)$

$0(0)^{* \star}$

$17(5 \cdot 7)$

$35(11 \cdot 7)$

$248(82 \cdot 7)^{*}$

\#Total number of women (300) and men (300); P-value obtained from One-way ANOVA $* P<0 \bullet 05$; $* * p<0.001$ 


\begin{tabular}{|c|c|c|}
\hline$>701$ & $16(5 \cdot 3)$ & $24(8)$ \\
\hline \multicolumn{3}{|c|}{ Atherogenic Index of Plasma (CVD risk) } \\
\hline Low & 135 (45) & $18(6 \cdot 0)$ \\
\hline Intermediate & $77(25 \bullet 7)$ & $5(1 \cdot 7)^{*}$ \\
\hline High & $88(29 \cdot 3)$ & $277(92 \cdot 3)^{\star \star}$ \\
\hline \multicolumn{3}{|c|}{ C-reactive protein (mg/L) } \\
\hline$<1 \cdot 00 \mathrm{mg} / \mathrm{L}$ & $50(16 \cdot 6)$ & $20(6 \cdot 7)$ \\
\hline $1 \cdot 00-5 \cdot 00 \mathrm{mg} / \mathrm{L}$ & $150(50 \bullet 0)$ & $110(36 \cdot 7)$ \\
\hline$>5 \mathrm{mg} / \mathrm{L}$ & $100(33 \cdot 4)$ & $170(56 \cdot 6)^{*}$ \\
\hline \multicolumn{3}{|c|}{$\begin{array}{l}\text { \#Total number of women (300) and men (300); } P \text {-value obtained from One-way ANOVA• }{ }^{*} P<0.05 \text {; } \\
\star_{*} p<0.001\end{array}$} \\
\hline
\end{tabular}

Moreover, both older men and women with high CVD risk based on AIP, had significantly elevated fasting blood glucose (women only), glycated hemoglobin A1C, LDL-C, total cholesterol, triglycerides, C-reactive protein, serum iron (women only) and albumin levels as well as were obese (Supplementary Table 1). Furthermore, using Pearson's correlation, high CVD risk based on their AIP associated positively with triglycerides $(r=0 \cdot 76, P=0.003)$, total cholesterol (men only: $r=0 \cdot 56, P=0.02), L D L-C$ (men only: $r=$ $0 \bullet 62, P=0 \cdot 001)$, C-reactive proteins $(r=0 \cdot 50, P=0 \cdot 03$ ) and BMI (women only: $r=0 \bullet 81, P=0 \bullet 002)$. In addition, high AIP correlated negatively with albumin levels $(r=-0 \bullet 62, P=0 \bullet 01)$ and HDL-C (men only: $r=$ $-0 \cdot 57, P=0 \cdot 05)$. Results not shown on Table.

Multivariate analysis based on the Multiple Regression in which age was the dependent variable and the biochemical markers, AIP and BMI were the independent variables revealed higher significant odds for BMI, triglycerides, C-reactive protein, and AIP (Supplementary Table 2).

\section{Discussion}

Although older adults are at increased risk of CVD, few studies were published focusing on the major risk factors in Al Madinah Al Munawarah. The current study revealed that older adults are at increased risk of CVD based on selected traditional and non-traditional risk factors. Thus, the study hypothesis was accepted. The current study revealed that older women and men had intermediate to high CVD risk based on their AIP values. The use of AIP as an atherogenic index is a strong predictor of myocardial infarction and atherosclerosis and the study findings supported other studies which indicated that high AIP is 
directly associated with older age, ${ }^{[20-21]}$ and could be used as a stand-alone index for cardiac risk estimation. ${ }^{[17-21]}$

Furthermore, studies indicated that serum albumin is inversely related to inflammatory processes, ${ }^{[13]}$ and hypoalbuminemia is strongly correlated with all-cause mortality and cardiovascular mortality. ${ }^{[22]}$ The current study revealed that a significant number of Saudi men (41\%) and women (54\%) had hypoalbuminemia. Previous studies have indicated that serum albumin is significantly correlated with steps per day and physical activity. ${ }^{[23]}$ Physical inactivity is very common amongst Saudi older adults and among other problems such as low protein intake, ${ }^{[19]}$ could have resulted in the low serum albumin levels.

Moreover, C-reactive protein has a direct role in promoting vascular inflammation, vessel damage and clinical CVD events and can predict the long-term risk of myocardial infarction and sudden cardiac death in healthy people. ${ }^{[16]}$ The current study showed that on average both older men and women had significantly elevated C-reactive protein values with $33 \%$ of the women and $57 \%$ of the men having very high levels. In addition, high AIPs among Saudi older adults significantly correlated with high C-reactive protein levels and this is true irrespective of the gender. Studies revealed that high C-reactive protein values are associated with a high global cardiovascular risk. ${ }^{[16]}$

Moreover, it is well known that diabetes mellitus is an independent risk factor for CVD. ${ }^{[11-12]}$ Metaanalysis and systemic reviews revealed that diabetes increases CVD risk by approximately twofold especially amongst those who are known diabetic compared to newly diagnosed diabetics. ${ }^{[24]}$ The current study supported this theory and revealed that most of the older men and women were already diabetic and their fasting blood glucose and glycated hemoglobin A1C were elevated (Table 2). Older adults with high risk of CVD based on their AIP also had higher glycated hemoglobin A1C although this association didn't reach to significance level in the Multiple Regression model.

Furthermore, previous studies conducted in Saudi Arabia reported that the prevalence of anemia among older adults is $13-18 \%$ with women more affected than men. ${ }^{[25]}$ Hemoglobin concentration could influence the cardiovascular system via oxygen supply and blood viscosity and anemia is shown to be an independent risk factor for CVD. ${ }^{[26]}$ The current study showed that both older men and women had low hemoglobin and serum iron levels (Table 2). The prevalence of anemia is very high and women with high risk for developing CVD as defined by high AIP, had the lowest serum iron levels (Supplementary Table 1).

One of the independent risk factors associated with the development of CVD is increased body weight which affects hemodynamics and heart structure. ${ }^{[3-6]}$ The current study found a significant number of older men and women being either overweight or obese; with men being more affected by the problem. Amongst women, high AIP values were significantly associated with high BMI $(r=0 \bullet 81, P=0 \bullet 002)$ and those with lower AIPs have either normal weight (women) or overweight (men). A previous study conducted in Al Madinah Al Munawarah on older adults revealed that the prevalence of obesity and 
overweight combined was $78 \%$ and $83 \%$ among older men and women respectively. ${ }^{[19]}$ One of the main reasons for the increased body weight in this community is the sedentary lifestyle and high carbohydrate intakes.

In conclusion, Saudi older men and women had increased risk for developing CVD based on their odd ratios and high prevalence of traditional and non-traditional risk factors. Based on the findings of the current study, urgent community-intervention programs should target older adults in Al Madinah Al Munawarah.

\section{Limitations Of The Study}

Although it is considered the first study to be carried out in geriatric population in Al Madinah Al Munawarah, there are still some limitations for our findings.

- The cross-sectional nature of the study design has its draw backs and potential bias and thus findings should be interpreted with caution. Ideally, it would have been more appropriate to conduct a longitudinal study to follow up those older adults for a certain period and report the actual risks for developing CVD based on traditional and non-traditional risk factors.

- In addition, the selection of sample was a convenient sampling method which means the study lost its randomization and as such generalization of the findings would be questioned. However, since it was not possible to obtain a representative sample through a computerized system, non-randomized sampling method was the most appropriate solution.

- Also, blood samples were only taken once, and this might have introduced bias due to the day to day variations. However, the inclusion of a large sample size at $95 \%$ confidence interval might have reduced this bias.

\section{Abbreviations}

AIP

Atherogenic Index of Plasma

ALT

Alanine transaminase

AST

Aspartate transaminase

BMI

Body Mass Index

$\mathrm{Cl}$

Confidence Interval

CVD

Cardiovascular diseases

HDL-C 
High density lipoprotein cholesterol

LDL-C

Low density lipoprotein cholesterol

WHO

World Health Organization

\section{Declarations}

\section{- Ethics approval and consent to participate:}

Ethical permission was obtained from the ethical committee at the Faculty of Applied Medical Sciences (Approval \# CLN 201703), Taibah University in Al Madinah Al Munawarah where the researchers are currently employed. Signed consent was also sought from older adults (A copy of the consent form is available upon request).

\section{- Consent to publish:}

Included in the consent to participate form

\section{- Availability of data and materials:}

The datasets used and/or analysed during the current study are available from the corresponding author on reasonable request.

\section{- Competing interests:}

The authors declare that they have no competing interests.

\section{- Funding:}

The study was self-funded by the authors.

\section{- Authors' Contributions:}

WM (The $1^{\text {st }}$ author): Laboratory work, Data entry and analysis, Part of the methodology Writing part of the result section.

$\mathrm{AE}$ (The corresponding author): Body composition measurements, Manuscript writing (Introduction, Methodology, Part of the result section, Discussion).

All authors read and approved the final manuscript 


\section{- Acknowledgements:}

The authors would like to thank all the participants for agreeing to take part in the study. Thanks also go

to the nurses who help in blood withdrawal and to the laboratory technician who prepared some of the samples.

\section{References}

1. Agarwalla R. Saikia AM•and Baruah R Assessment of the nutritional status of the elderly and its correlates. J Family Com Med. 2015;22(1):39-43. doi:10.4103/2230-8229.149588.

2. Ministry of Health Cardiovascular diseases cause $42 \%$ of non-communicable diseases deaths in the Kingdom: Ministry of health; 2013, Available from: https://www•moh•gov•sa/en/Ministry/MediaCenter/News/Pages/News-2013-10-30002•aspx•Accessed 12 January 2020.

3. Amarya S, Singh K, Sabharwal. M•Changes during aging and their association with malnutrition $J$ Clin Geront Geriat 2015•6(3), pp•78-84•.

4. Ortega FB, Lavie CJ, Blair SN, Obesity, Cardiovascular Disease. Circul Res. 2016;118(11):1752-70. https://doi.org/10.1161/CIRCRESAHA.115.306883.

5. Leslie W, Hankey C. Aging, nutritional status and health. Healthcare J. 2015;3(3):648-58. https://www・ncbi•nlm•nih•gov/pmc/articles/PMC4939559/.

6. Perry L. Is BMI an accurate measure of nutritional status in older people. Nurs Times. 2009;105(37):12.

7. Fuchs FD, Whelton PK, High Blood Pressure. and Cardiovascular Disease Hypertension. 2020;75:285-92. https://doi.org/10.1161/HYPERTENSIONAHA.119.14240.

8. Lewington S, Clarke R, Qizilbash N, Peto R, Collins R Age-specific relevance of usual blood pressure to vascular mortality: A meta-analysis of individual data for one million adults in 61 prospective studies• Lancet 2002;360(9349):1903-13\&\#8729.

9. Clark CE, Taylor RS, Shore AC, Ukoumunne OC, Campbell JL Association of a difference in systolic blood pressure between arms with vascular disease and mortality: a systematic review and metaanalysis Lancet 2012;379(9819):905 - 14\&\#8729.

10. Lewington S, Whitlock G, Clarke R, Sherliker P, Emberson J, Halsey J, et al. Blood cholesterol and vascular mortality by age, sex, and blood pressure: a meta-analysis of individual data from 61 prospective studies with 55,000 vascular deaths Lancet 2007;370(9602):1829-39\&\#8729.

11. Matthias B, Ignacio F-G, John JY, Paul JK, Elie AA, Ping W, et al. Association between change in high density lipoprotein cholesterol and cardiovascular disease morbidity and mortality: systematic review and meta-regression analysis• BMJ 2009;338\&\#8729.

12. Sarwar N, Danesh J, Eiriksdottir G, Sigurdsson G, Wareham N, Bingham S, et al. Triglycerides and the Risk of Coronary Heart Disease: 10158 Incident Cases Among 262525 Participants in 29 Western 
Prospective Studies Circulation 2007;115(4):450 - 58\&\#8729.

13. Sun DL, Wang JH, Jiang B, Li LS, Wu L, Wu HY, et al. Metabolic syndrome vs its components for prediction of cardiovascular mortality: A cohort study in Chinese elderly adult. Journal of Geriat Cardiol. 2012;9(2):123-9.

14. Chien SC, Chen CY, Lin CF. Yeh Hl•Critical appraisal of the role of serum albumin in cardiovascular disease• Biomark Res•2017;5:31• doi:10•1186/s40364-017-0111-x.

15. Ganguly P, Alam SF. Role of homocysteine in the development of cardiovascular disease. Nutr J. 2015;14:6. doi:10.1186/1475-2891-14-6.

16. Tang Y, Fung E, Xu A. Lan HY C-reactive protein and ageing. Clin Exper Pharm Physio. 2017;44(9):914. https://doi•org/10•1111/1440-1681•12758.

17. Puzianowska-Kuznicka M, Owczarz M, Wieczorowska-Tobis $K$, et al Interleukin- 6 and C-reactive protein, successful aging, and mortality: The PolSenior study Immun Ageing•2016;13:21•

18. Bendzala M, Sabaka P, Caprnda M, et al. Atherogenic index of plasma is positively associated with the risk of all-cause death in elderly women: A 10-year follow-up•. Wien Klin Wochenschr. 2017;129(21-22):793-8•. i:10•1007/s00508-017-1264-1 • (: do.

19. 25 El. Shikieri AB, Saeed WMM, Alharbi A, et al Nutritional Status and Associated Risk Factors amongst Older Adults in Al Madinah Al Munawarah EC Nutrition 2019; 14(9):637-45.

20. Nwagha UI, Ikekpeazu EJ, Ejezie FE, Neboh EE. Maduka IC.Atherogenic index of plasma as useful predictor of cardiovascular risk among postmenopausal women in Enugu, Nigeria Afr Health Sci•2010;10(3):248-252•.

21. Khazaal MS. Atherogenic index of plasma as a parameter in predicting cardiovascular risk in males compared to the conventional dyslipidemic indices. Karbala Journal of Medicine. 2013;6:1506-31.

22. Danesh J, Collins R, Appleby P. Peto R• Association of fibrinogen, C-reactive protein, albumin, or leukocyte count with coronary heart disease: meta-analyses of prospective studies• JAMA•1998;279(18):1477-1482• doi: 10•1001/jama•279•18•1477.

23. Oishi $D$, Koitabashi $K$, Hiraki $K$, et al. Physical activity is associated with serum albumin in peritoneal dialysis patients•. Adv Perit Dial•. 2012;28:148 - 52•.

24. Sattar N. Revisiting the links between glycaemia, diabetes and cardiovascular disease•. Diabetologia. 2013;56:686-95. https://doi•org/10•1007/s00125-012-2817-5.

25. Alsaeed $\mathrm{AH} \bullet A n$. Analysis of Hematological Parameters to Assess the Prevalence of Anemia in Elderly Subjects from Saudi Arabia Gen Test Mol Bio 2011:697-700 http://doi•org/10•1089/gtmb•2011•0030.

26. Sarnak MJ, Tighiouart H, Manjunath G, MacLeod B, Griffith J, Salem D. Levey AS• Anemia as a risk factor for cardiovascular disease in the Atherosclerosis Risk in Communities (ARIC). Study $\bullet J$ Am Coll Cardiol. 2002;40:27-33.

\section{Supplementary Files}


This is a list of supplementary files associated with this preprint. Click to download.

- SupplementaryTableselderlystudyCVD2020.xIsx 